\title{
Level of self-care practice among diabetic patients in Ethiopia: a systematic review and meta-analysis
}

Daniel Bekele Ketema ${ }^{1 *}$ D, Cheru Tesema Leshargie ${ }^{1}$, Getiye Dejenu Kibret ${ }^{1}$, Moges Agazhe Assemie $^{1}$, Alehegn Aderaw Alamneh², Getachew Mullu Kassa' and Animut Alebel ${ }^{3}$

\begin{abstract}
Background: Diabetes Mellitus (DM) is increasingly become a serious global public health concern in developed and developing countries including Ethiopia. It imposes significant burden of care on the individual, health care professionals and health system. As the result, immense need of self-care behaviors in multiple domains like food choices, physical activity, foot care, and blood glucose monitoring is required. However, there is no national study on diabetic self-care practices in Ethiopia. This meta-analysis, therefore, aims to estimate the pooled level of selfcare practice among individuals living with diabetes mellitus in Ethiopia.
\end{abstract}

Methods: The systematic review was reported according to the Preferred Reporting Items for Systematic Reviews and Meta-Analysis (PRISMA) guideline. We systematically searched the databases: PubMed /MEDLINE, EMBASE, Google Scholar, and Science Direct for studies conducted in Ethiopia about self-care practice of diabetes patients. We have included all cross-sectional studies, which were published until August 20th,2019. Data were analyzed using STATA $^{\text {TM }}$ version 14.1 software, and the pooled prevalence with 95\% confidence intervals (Cl) were presented using tables and forest plots. The presence of statistical heterogeneity within the included studies was evaluated using I-squared statistic. We used Higgins and Egger's test to identify evidence of publication bias. The randomeffects meta-analysis model was employed to estimate the pooled proportion of good diabetic self-care practices.

Results: We included 35 studies (with 11,103 participants) in this meta-analysis. The overall pooled prevalence of good diabetes self-care behavior among diabetic patients was 49\% (95\% Cl:43, 56\%). When categorized by the major domains of diabetes self-care, the pooled estimate of dietary practice was 50\% (95\% Cl:42, 58\%), for selfmonitoring of blood glucose was $28 \%$ (95\% Cl:19, 37\%), for recommended physical activity was 49\% (95\% Cl:38, 59\%), and for diabetic foot-care was 58\% (95\% Cl: 41, 74\%).

Conclusion: More than half of diabetic patients in Ethiopia had poor diabetes self-care practice. High percentage of diabetic patients also had poor dietary practice, self- monitoring of blood glucose, physical activity, and diabetic foot care. Therefore, intervention programs should focus on improving the knowledge level of diabetic patients to improve the self-care practice of diabetic patients.

Keywords: Diabetes, Self-care, Blood glucose monitoring, Systematic review, Meta-analysis

\footnotetext{
* Correspondence: danibekele2009@gmail.com

'Department of Public Health, College of Health Sciences, Debre Markos

University, P.O. Box 269, Debre Markos, Ethiopia

Full list of author information is available at the end of the article
}

C C The Author(s). 2020 Open Access This article is licensed under a Creative Commons Attribution 4.0 International License, which permits use, sharing, adaptation, distribution and reproduction in any medium or format, as long as you give appropriate credit to the original author(s) and the source, provide a link to the Creative Commons licence, and indicate if changes were made. The images or other third party material in this article are included in the article's Creative Commons licence, unless indicated otherwise in a credit line to the material. If material is not included in the article's Creative Commons licence and your intended use is not permitted by statutory regulation or exceeds the permitted use, you will need to obtain permission directly from the copyright holder. To view a copy of this licence, visit http://creativecommons.org/licenses/by/4.0/ The Creative Commons Public Domain Dedication waiver (http://creativecommons.org/publicdomain/zero/1.0/) applies to the data made available in this article, unless otherwise stated in a credit line to the data. 


\section{Background}

Diabetes Mellitus (DM) related clinical complications are most important causes of morbidity and mortality, and have considerable effect on the patients' quality of life and productivity [1,2]. Globally, approximately half a billion people live with diabetes, and almost $80 \%$ of diabetes burden was shared by low and middle income countries including Ethiopia [3, 4]. According to the International Diabetes Federation (IDF) report, there were 2,567,900 cases of diabetes in Ethiopia making the adult prevalence of 5.2\% [3]. Due to the rapid expansion of urbanization, unhealthy diets, and sedentary change of life style, the incidence of DM keeps increasing $[3,5]$.. The chronic nature of DM causes significant personal suffering and economical difficulty in the families [3, 4, $6,7]$. Moreover, DM have not impose only personal suffering; due to its continued needs and demands of individual effort, it was considered as a major challenge for health care workers as well [8].

In order to reduce the burden posed to health systems and affected individuals, patients with diabetes need to adopt certain diabetes self-care behaviors. Diabetes selfcare behavior is defined as an evolutionary process of development of knowledge or awareness by learning to survive with the complex nature of the diabetes in a social context $[4,6,9]$. American Diabetes Association (ADA) has set a list of essential self-care activities, which used for monitoring blood glucose at recommended level, prevent diabetic complications and improving the quality of life of diabetic patients [6, 7]. These diabetes self-care includes: self-monitoring of blood glucose (SMBG), nutrition, physical activity and diabetic foot care $[1,6,10]$. Diabetes is a complex, chronic illness requiring continuous medical care with multifactorial riskreduction strategies beyond glycemic control [3]. Several studies reported that, ongoing patient self-care education and support are critical to preventing acute complications and reducing the risk of long-term complications $[3,11,12]$.

DM self-care activities are owned by patients and their families; as a result, there should be consistent and effective measure for diabetes self-care through dietary and lifestyle modification complemented with supportive role of health care providers [4, 13-15]. Self-monitoring of glycemic combined with regular physical activity are considered as a cornerstone of diabetes cares to ensure patient participation in achieving and maintaining at recommended level of blood glucose [6, 16-19].

The majority of patients with diabetes can significantly reduce the chance of developing long-term complication by improving self-care activities. To date, the level of DM self- care practice have been reported in several studies in Ethiopia, which ranges from 22.5 to $76.8 \%$ [1, 20-35]. However, most of these studies have offered district level information. As a result of variability of findings across previously existing studies, producing pooled proportion of DM self-care at the national level is needed. Moreover, comprehensive estimates of the extent of DM self-care levels are needed for the programmatic management of diabetes within the context of diabetes care. Therefore, this systematic review and meta-analysis was undertaken to produce pooled estimates of DM self-care levels in Ethiopia.

\section{Methods}

Data source and search strategy

Published and unpublished research articles that were conducted to assess a minimum of one variety of diabetic self-care (overall diabetic self-care, diet, physical activity, self-monitoring of glucose, foot care) in Ethiopia were included during this study. An intensive search was done from PubMed/MEDLINE, and EMBASE online databases to access articles done on the diabetes self-care practices. Moreover, Google Scholar and Science direct were accustomed to retrieve articles. Besides, reference lists of screened studies were checked. The search was administered by two authors (DBK and AA) independently. The term 'diabetes' was searched with all of the subsequent terms as a mix of free text and thesaurus terms in numerous variations: diabetes self-care, dietary care, foot care, physical activity, glycemic control, and Ethiopia. Moreover, the subsequent keywords were accustomed to retrieve studies from PubMed database; ((((Diabetes self-care) OR diabetes dietary care) OR diabetes foot care) OR diabetes physical activity) OR selfmonitoring of blood glucose) AND Ethiopia. Studies that were relevant by title and abstract were assessed by full text to see those that provided adequate data to be included in our meta-analysis. This systematic review and meta-analysis was reported per preferred reporting items for Systematic Review and Meta-Analysis (PRISMA) guideline [36].

\section{Inclusion criteria}

- Study setting: Studies done in Ethiopia.

- Study participants: Studies conducted among all Diabetes Mellitus patients.

- Publication status: All published and unpublished articles.

- Language: Only studies published in the English were included

- Types of studies: Studies that employed observational study design.

- Publication date: The authors included articles published until August 20,2019 


\section{Exclusion criteria}

- Despite the above-mentioned preset eligibility criteria, articles which we were unable to access the full-texts after two email contacts of the principal investigator of the particular study were excluded from the final analysis.

\section{Outcome measures}

Diabetes self-care was defined as good self-care practice and poor self-care practice $[24,25]$. In this metaanalysis, we measure diabetes self-care practice using four domains: dietary practices, engagement in regular exercise, foot-care and blood glucose monitoring $[3,6]$.

\section{Dietary practice}

Patients who scored above the mean value for the response were classified as having good dietary practice and poor dietary practice otherwise.

\section{Glycemic control}

The level of glycemic control was indicated as 'good glycemic control' when FBS results were between 70 and $130 \mathrm{mg} / \mathrm{dL}$ (i.e. an average of three measures at different visits).

\section{Regular exercise}

20-30 min of aerobic exercise such as walking or swimming 3-4 days per week [37].

\section{Foot care practice}

a total practice score of $\geq 50 \%$ of maximum score is categorized as good foot care practice, while a total practice less than a score of $50 \%$ categorized as poor foot care practice [38].

\section{Data extraction and quality assessment}

Seven authors (DBK, AAA, GDK, AA, AAA, and CTL) done data abstraction using pre-piloted data extraction format prepared in Microsoft ${ }^{\mathrm{TM}}$ Excel spreadsheet. The seventh author (GMK) reconciled any disagreements among the six authors. From each study, we have extracted data on the study location, region, publication year, study design, sample size, and first author name for the overall diabetes self-care and for each domains of diabetes self-care practice (Supplementary File 1, Supplementary File 2, Supplementary File 3, Supplementary File 4, and Supplementary File 5).

The quality of included studies has been assessed in accordance with the Newcastle-Ottawa Quality assessment scale [39]. Two independent reviewers (DBK \& GDK) done a full-text quality assessment. Disagreement between the two reviewers was found to be very low (1.5\%) and they resolved this by discussion. Then, a combined quality score ranging from 0 to 10 was assigned to each included articles.

\section{Heterogeneity and publication bias}

The presence of statistical heterogeneity within the included articles was assessed using I-squared statistic. Accordingly, heterogeneity was classified as low, moderate, or high when the value of I-squared were 25, 50, and $75 \%$, respectively [40]. Begg and Egger weighted regression method were employed to detect evidence of publication bias. $P$-value $<0.05$ was considered as presence of significant publication bias [41].

\section{Statistical analysis}

Relevant data from every primary study was extracted using a Microsoft Excel format. Data were then exported to STATA ${ }^{\mathrm{Tm}}$ Version fourteen software package for analysis. The pooled estimate was computed using metan SATA command. Results were presented using tables and forest plots with 95\% confidence intervals (CI). We have used Higgins and Egger's test to identify publication bias. As a result of high level of heterogeneity among included studies, random-effects model was used to produce Der Simonian and Laird's pooled estimate. Additional advanced statistical analyses like univariate meta-regression and sensitivity analysis were performed to identify the potential sources of heterogeneity and to assess the influence of a single study on the overall pooled estimate respectively.

\section{Results}

\section{Selection and identification of studies}

A total of 969 articles were retrieved from electronic databases and other sources. Title and abstracts were screened and duplicated or irrelevant articles were removed using EndNote $\times 7$. Accordingly, 552 duplicate articles were removed. From the remaining 417articles, 382 articles were excluded because their titles and abstracts were not in-line with our inclusion criteria (not report the outcome of the interest, studies conducted outside of Ethiopia). Finally, a total of 35 articles were included for this systematic review and meta-analysis. The detailed selection procedures were described in Fig. 1.

\section{Description of included studies}

We included 35 cross-sectional studies (with 11,103 participants) in the final systematic review and metaanalysis. The smallest sample size was 102 obtained from a study conducted at Ambo Hospital Oromia region of Ethiopia [35]. Whereas, the largest sample size was 419 reported from a study at Tikur Anbessa Specialized Hospital, Addis Ababa, Ethiopia [42]. The detail characteristics of included studies was presented in Table 1. 


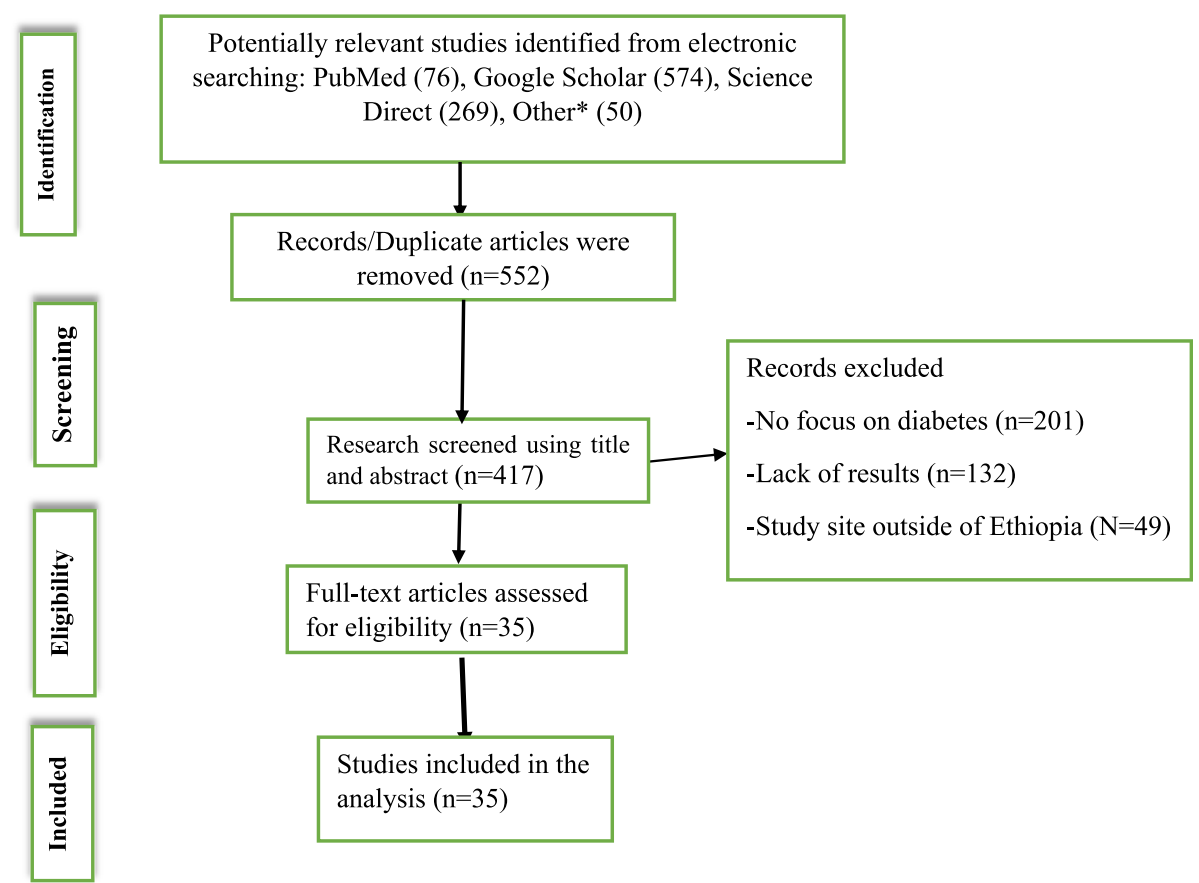

Fig. 1 PRISMA flow diagram which shows the studies selection of the meta-analysis on levels of diabetes self-care practice in Ethiopia

In the current meta-analysis, seven regions and one administrative town in the country were represented. Most studies took place in Oromia Region $(n=13)$ [2, $17,22,25,28,29,35,37,48,49,51,52]$ and Amhara Region $(n=9)$ [4, 16, 20, 27, 34, 38, 44, 46, 53]; followed by Tigray Region $(n=4)$ [23, 31, 32, 47], South Nation Nationality of People (SNNP), $n=3)$ ) [21, 26, 33]; Addis Ababa ( $n=4)$ [30, 42, 45, 54]; Benishangul Gumuz region [24], and Harari region [1] ( $n=1$ each). Most studies dealt with self-monitoring of blood glucose (SMBG) $(n=21)$, followed by overall diabetes self-care $(n=16)$, assessment of dietary practice $(n=15)$, and engagement in physical activity $(n=14)$. Only eight studies assessed diabetic foot-care. Quality assessment using the Newcastle-Ottawa Scale for cross-sectional studies showed a quality score ranging from 4 to 9 (Table 1).

\section{Diabetes self-care practices \\ Overall diabetes self-care practice}

From a total of 35 cross-sectional studies, seventeen studies provided information on overall diabetes selfcare practices. As described in the forest plot (Fig. 2), the pooled estimate of the overall diabetes self-care practice was $49 \%$ (95\% CI:43,56\%). High heterogeneity was observed (I-squared $=96.09 \%$ ), but there was no evidence of publication bias using Egger's test ( $p$-value = 0.229 ). To minimize the potential random variations between the included studies, we performed a sub-group analysis by taking regions of the country where studies conducted. Accordingly, the highest level of diabetes self-care practice was observed from SNNP 58\% (95\% CI:55, 78\%), followed by Oromia region 55\% (95\% CI: 51, 59\%) (Table 2).

A meta-regression was performed using publication year and sample size as covariates to explore the possible source of heterogeneity. However, there is no significant evidence that indicate the existence of heterogeneity, which explained by using these variables (Table 3). Furthermore, to identify the effect of single study on the overall pooled estimate, we did a sensitivity analysis using a random effects model. Accordingly, there is no evidence of single study influence on the overall pooled estimate.

\section{Diabetes self-care practices across major domains (dietary practices, physical activity, foot-care and blood glucose monitoring)}

In this meta-analysis, we measure diabetes self-care practice using four domains: dietary practices, engagement in regular exercise, foot-care and blood glucose monitoring. Accordingly, fourteen studies included information on dietary self-care behaviors and reported on patients' behavior regarding dietary practice. In this meta-analysis, the pooled level estimate of good dietary practice of diabetic patients was 50\% (95\% CI:42, 58\%) (Fig. 3). Concerning on blood glucose monitoring, twenty-one observational studies reported patients' behavior regarding monitoring of blood glucose. As detailed in Fig. 4, the lowest percentage of diabetic patients that have good glycemic control practice were 28\% (95\% 
Table 1 Study characteristics of included articles for the final systematic review and meta-analysis on diabetes self-care among diabetic patients in Ethiopia

\begin{tabular}{|c|c|c|c|c|c|c|c|c|c|c|}
\hline \multirow[t]{2}{*}{ No. } & \multirow[t]{2}{*}{ Author } & \multirow[t]{2}{*}{ Year } & \multirow[t]{2}{*}{ Region } & \multirow{2}{*}{$\begin{array}{l}\text { Sample } \\
\text { size }\end{array}$} & \multicolumn{5}{|c|}{ Reported outcome percentage $(95 \% \mathrm{Cl})$} & \multirow{2}{*}{$\begin{array}{l}\text { Quality } \\
\text { assessment score }\end{array}$} \\
\hline & & & & & $\begin{array}{l}\text { Overall self- } \\
\text { care }\end{array}$ & $\begin{array}{l}\text { Dietary- } \\
\text { practice }\end{array}$ & $\begin{array}{l}\text { Physical- } \\
\text { activity }\end{array}$ & SMBG & Foot-care & \\
\hline 1 & $\begin{array}{l}\text { Berhe, K, } \\
\text { et al. [23]. }\end{array}$ & 2017 & Tigray & 310 & $\begin{array}{l}49.4(43.8, \\
54.9)\end{array}$ & $\begin{array}{l}32.9(27.7 \\
38.1)\end{array}$ & $\begin{array}{l}74(69.1 \\
78.8)\end{array}$ & $14(10.1,17.8)$ & $\begin{array}{l}51.3(45.7, \\
56.8)\end{array}$ & 7 \\
\hline 2 & $\begin{array}{l}\text { Kassahun CW. } \\
\text { et al. [2] }\end{array}$ & 2017 & Oromia & 284 & $\begin{array}{l}56.6(31.5, \\
81.7)\end{array}$ & - & - & - & - & 8 \\
\hline 3 & $\begin{array}{l}\text { Chali, S.W. } \\
\text { et al. [24] }\end{array}$ & 2018 & Benishangul & 383 & $\begin{array}{l}54.3(49.3, \\
59.3)\end{array}$ & - & - & - & - & 6 \\
\hline 4 & $\begin{array}{l}\text { Worku, A, } \\
\text { et al. [43]. }\end{array}$ & 2015 & $\begin{array}{l}\text { Addis } \\
\text { Ababa }\end{array}$ & 403 & - & $\begin{array}{l}48.6(43.7, \\
53.5)\end{array}$ & - & $41.2(36.4,46.0)$ & - & 4 \\
\hline 5 & $\begin{array}{l}\text { Demilew YM. } \\
\text { et al. [44] }\end{array}$ & 2018 & Amhara & 401 & - & $\begin{array}{l}35.9(31.2, \\
40.6)\end{array}$ & - & - & - & 8 \\
\hline 6 & $\begin{array}{l}\text { Tiruneh SA.., } \\
\text { et al. [34] }\end{array}$ & 2019 & Amhara & 385 & $\begin{array}{l}63.1(58.8, \\
67.9)\end{array}$ & - & - & - & - & 5 \\
\hline 7 & $\begin{array}{l}\text { Gesesew H. } \\
\text { et al. [28] }\end{array}$ & 2016 & Oromia & 309 & - & - & $\begin{array}{l}49.2(43.6 \\
54.8)\end{array}$ & $71(65.0,76.0)$ & - & 7 \\
\hline 8 & $\begin{array}{l}\text { Hailu, E., } \\
\text { et al. [37] }\end{array}$ & 2012 & Oromia & 343 & - & $\begin{array}{l}55.6(50.3, \\
60.8)\end{array}$ & $\begin{array}{l}64.9(59.8, \\
69.9)\end{array}$ & $2.6(0.91,4.3)$ & $\begin{array}{l}82.9(78.9 \\
86.8)\end{array}$ & 9 \\
\hline 9 & $\begin{array}{l}\text { Niguse } \mathrm{H} \text {. } \\
\text { et al. [32] }\end{array}$ & 2016 & Tigray & 338 & $\begin{array}{l}25.5(20.8, \\
30.1)\end{array}$ & - & - & - & - & 6 \\
\hline 10 & $\begin{array}{l}\text { Ayele K. } \\
\text { et al. [1] }\end{array}$ & 2012 & Harai & 222 & $\begin{array}{l}39.2(32.8, \\
45.8)\end{array}$ & $\begin{array}{l}55.7(51.2, \\
64.2)\end{array}$ & $\begin{array}{l}31.1 \text { (25.0, } \\
37.2)\end{array}$ & $2.3(0.32,4.3)$ & - & 7 \\
\hline 11 & $\begin{array}{l}\text { Feleke SA. } \\
\text { et al. [27] }\end{array}$ & 2013 & Amhara & 410 & $\begin{array}{l}36.8 \text { (32.1, } \\
41.5)\end{array}$ & $\begin{array}{l}57.1(52.3, \\
61.9)\end{array}$ & - & $23.6(19.5,27.7)$ & - & 9 \\
\hline 12 & $\begin{array}{l}\text { Addisu,Y, } \\
\text { et al. [21] }\end{array}$ & 2014 & SNNP & 310 & $\begin{array}{l}76.8(72.1, \\
81.5)\end{array}$ & $\begin{array}{l}49.7(44.1, \\
55.3)\end{array}$ & $\begin{array}{l}44.5(38.9 \\
50.0)\end{array}$ & $20.0(15.5,24.4)$ & - & 5 \\
\hline 13 & $\begin{array}{l}\text { Bonger, } Z \text {, } \\
\text { et al. [45] }\end{array}$ & 2018 & $\begin{array}{l}\text { Addis } \\
\text { Ababa }\end{array}$ & 419 & - & $\begin{array}{l}24.1(20.0, \\
28.2)\end{array}$ & $\begin{array}{l}46.3(41.5, \\
51.0)\end{array}$ & $16.5(12.9,20.0)$ & - & 8 \\
\hline 14 & $\begin{array}{l}\text { Kassahun, T., } \\
\text { et al. [29] }\end{array}$ & 2016 & Oromia & 309 & $\begin{array}{l}49.2(43.6, \\
54.8)\end{array}$ & - & - & $29.1(24.0,34.2)$ & - & 6 \\
\hline 15 & $\begin{array}{l}\text { Aklilu, T., } \\
\text { et al [4] }\end{array}$ & 2014 & Amhara & 303 & - & $\begin{array}{l}80.9(76.5 \\
85.3)\end{array}$ & $\begin{array}{l}45.9(40.3, \\
51.5)\end{array}$ & $20.1(15.6,24.6)$ & $\begin{array}{l}80.2(75.7 \\
84.7)\end{array}$ & 4 \\
\hline 16 & $\begin{array}{l}\text { Mariye T, } \\
\text { et al. [31] }\end{array}$ & 2018 & Tigray & 284 & $\begin{array}{l}37.3(31.7, \\
42.9)\end{array}$ & - & - & - & - & 7 \\
\hline 17 & $\begin{array}{l}\text { Dedefo. G., } \\
\text { et al. [25] }\end{array}$ & 2019 & Oromia & 252 & $\begin{array}{l}60.7 \text { (54.6, } \\
66.7)\end{array}$ & $\begin{array}{l}69.4 \text { (63.7, } \\
75.1)\end{array}$ & $\begin{array}{l}63.5(57.5 \\
69.4)\end{array}$ & $40.5(34.4,46.5)$ & $\begin{array}{l}82.9(78.2, \\
87.5)\end{array}$ & 5 \\
\hline 18 & $\begin{array}{l}\text { Mariam. G., } \\
\text { et al. [46] }\end{array}$ & 2017 & Amhara & 279 & - & $\begin{array}{l}97.8(96.0 \\
99.5)\end{array}$ & $\begin{array}{l}81.7(77.2, \\
86.2)\end{array}$ & $63.4(57.7,69.1)$ & $\begin{array}{l}36.6(30.9, \\
42.2)\end{array}$ & 9 \\
\hline 19 & $\begin{array}{l}\text { Amente, T., } \\
\text { et al. [22] }\end{array}$ & 2014 & Oromia & 254 & $55(48.9,61.1)$ & - & - & - & - & 6 \\
\hline 20 & $\begin{array}{l}\text { Abate, T.W, } \\
\text { et al. [20] }\end{array}$ & 2018 & Amhara & 416 & $\begin{array}{l}28.4(24.0, \\
32.7)\end{array}$ & - & - & - & - & 5 \\
\hline 21 & $\begin{array}{l}\text { Deribe, B. } \\
\text { et al. [26] }\end{array}$ & 2014 & SNNP & 216 & $\begin{array}{l}55.6(49.7, \\
61.4)\end{array}$ & - & - & - & $\begin{array}{l}55.1(48.5, \\
61.7)\end{array}$ & 4 \\
\hline 22 & $\begin{array}{l}\text { Gebrekirstos K. } \\
\text { et al. [47] }\end{array}$ & 2015 & Tigray & 319 & - & - & - & - & $\begin{array}{l}19.3(14.2, \\
24.4)\end{array}$ & 7 \\
\hline 23 & $\begin{array}{l}\text { Sorato, M. } \\
\text { et al. [33] }\end{array}$ & 2016 & SNNP & 194 & $\begin{array}{l}41.2(34.3, \\
48.1)\end{array}$ & $\begin{array}{l}82.5(77.1 \\
87.8)\end{array}$ & $\begin{array}{l}50.5(43.5 \\
57.5)\end{array}$ & $5.7(2.4,8.9)$ & - & 8 \\
\hline 24 & $\begin{array}{l}\text { Gurmu, Y. } \\
\text { et al. [48] }\end{array}$ & 2018 & Oromia & 257 & $\begin{array}{l}54.5 \text { (48.4, } \\
60.6)\end{array}$ & - & & - & - & 9 \\
\hline 25 & $\begin{array}{l}\text { Woldu, M., } \\
\text { et al. [35] }\end{array}$ & 2014 & Oromia & 102 & - & $\begin{array}{l}58.8(49.2, \\
68.3)\end{array}$ & $\begin{array}{l}50(40.3 \\
59.7)\end{array}$ & $83.3(76.0,90.5)$ & - & 6 \\
\hline
\end{tabular}


Table 1 Study characteristics of included articles for the final systematic review and meta-analysis on diabetes self-care among diabetic patients in Ethiopia (Continued)

\begin{tabular}{|c|c|c|c|c|c|c|c|c|c|c|}
\hline \multirow{2}{*}{$\frac{\text { No. }}{26}$} & \multirow{2}{*}{$\begin{array}{l}\text { Author } \\
\text { Tekalegn, Y., } \\
\text { et al. [42] }\end{array}$} & \multirow{2}{*}{$\begin{array}{l}\text { Year } \\
2018\end{array}$} & \multirow{2}{*}{$\begin{array}{l}\text { Region } \\
\text { Addis } \\
\text { Ababa }\end{array}$} & \multirow{2}{*}{$\begin{array}{l}\text { Sample } \\
\text { size }\end{array}$} & \multicolumn{5}{|c|}{ Reported outcome percentage ( $95 \% \mathrm{Cl}$ ) } & \multirow{2}{*}{$\begin{array}{l}\text { Quality } \\
\text { assessment score } \\
5\end{array}$} \\
\hline & & & & & - & $\begin{array}{l}42.5(37.7, \\
47.3)\end{array}$ & $\begin{array}{l}54.4(49.6, \\
59.2)\end{array}$ & $15(11.5,18.4)$ & - & \\
\hline 27 & $\begin{array}{l}\text { Tegegne GT, } \\
\text { et al. [49] }\end{array}$ & 2015 & Oromia & 111 & - & - & $\begin{array}{l}18(10.8 \\
25.1)\end{array}$ & $23.4(15.5,31.3)$ & - & 8 \\
\hline 28 & $\begin{array}{l}\text { Tamirat A, } \\
\text { et al. [50] }\end{array}$ & 2014 & Oromia & 319 & - & - & $\begin{array}{l}11.9(8.3, \\
15.4)\end{array}$ & - & - & 8 \\
\hline 29 & $\begin{array}{l}\text { Wabe T, } \\
\text { et al. [51] }\end{array}$ & 2011 & Oromia & 384 & - & - & - & $41.9(36.9,46.8)$ & - & 4 \\
\hline 30 & $\begin{array}{l}\text { Angamo T, } \\
\text { et al. [52] }\end{array}$ & 2013 & Oromia & 284 & - & - & - & $18.3(13.8,22.8)$ & - & 8 \\
\hline 31 & $\begin{array}{l}\text { Yigezu DM. } \\
\text { et al. [17] }\end{array}$ & 2017 & Oromia & 174 & - & - & - & $40.8(33.5,48.1)$ & - & 5 \\
\hline 32 & $\begin{array}{l}\text { Fasil A. } \\
\text { et al. [16] }\end{array}$ & 2019 & Amhara & 367 & - & - & - & $39.5(34.5,44.5)$ & - & 6 \\
\hline 33 & $\begin{array}{l}\text { Seid A. } \\
\text { et al. [38] }\end{array}$ & 2014 & Amhara & 313 & - & - & - & - & $\begin{array}{l}53(47.5 \\
58.0)\end{array}$ & 8 \\
\hline 34 & $\begin{array}{l}\text { Mamo M. } \\
\text { et al. [30] }\end{array}$ & 2016 & $\begin{array}{l}\text { Addis } \\
\text { Ababa }\end{array}$ & 646 & $\begin{array}{l}60.3(56.5, \\
64.0)\end{array}$ & - & - & - & - & 9 \\
\hline 35 & $\begin{array}{l}\text { Abebe SM. } \\
\text { et al. [53] }\end{array}$ & 2015 & Amhara & 391 & - & - & - & $35.3(30.5,40.0)$ & - & 4 \\
\hline
\end{tabular}

SMBG Self-Monitoring of Blood Glucose

The dash-line (--) indicate a research not reported particular outcome

SNNP South Nation Nationality of people

$\mathrm{Cl}$ Confidence Interval

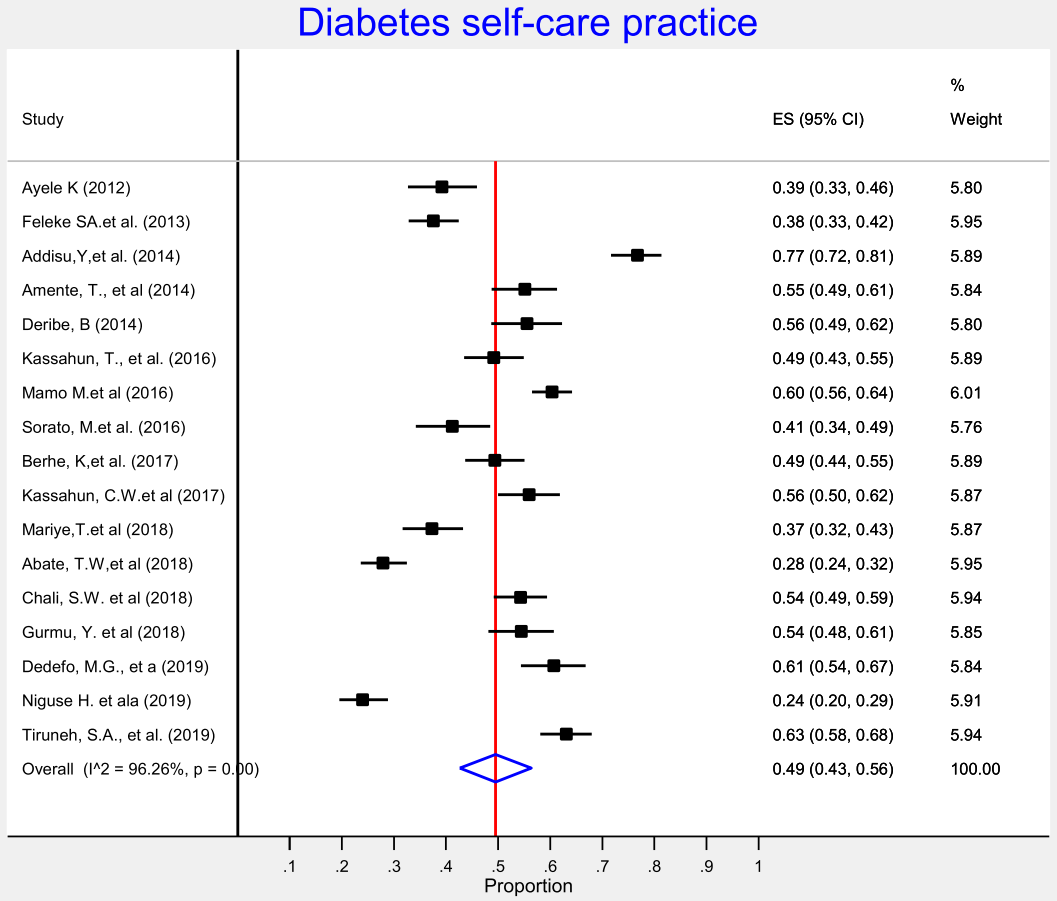

Fig. 2 Meta-analysis (forest plot) of the proportion of overall good self-care practice among diabetic patients in Ethiopia 
Table 2 Subgroup level of overall diabetes self-care practice among diabetic patients in Ethiopia by region, 2019

\begin{tabular}{lllll}
\hline Variable & Characteristics & Included studies & Sample size & Estimate of overall DM self-care \% (95\% Cl) \\
\hline Region & Amhara & 3 & 1211 & $43(23,63)$ \\
& Oromia & 5 & 1356 & $55(55,59)$ \\
& SNNPR & 3 & 720 & $58(55,0.78)$ \\
& Tigray & 3 & 932 & $37(22,52)$ \\
& Benishangul Gumz & 1 & 383 & $54(49,59)$ \\
& Harari & 1 & 222 & $39(33,46)$ \\
& Addis Ababa & 1 & 646 & $60(56,64)$ \\
\hline
\end{tabular}

CI: $19,37 \%)$. That is, $28 \%$ of diabetic patients selfmonitored and kept their blood glucose levels at recommended level. In addition, fourteen observational studies measured physical activity practice of DM patients. The highest percentage of DM patients who had adequate regular exercise was reported at the University of Gondar Referral Hospital, Amhara region, Ethiopia [46]. As presented in the forest plot (Fig. 5), the pooled level of adequate physical exercise was 49\% (95\% CI: 38, 59\%), which means $49 \%$ of diabetic patients had practiced physical activity that met the recommended guidelines. Moreover, eight observational studies reported on the diabetic patients practice on the foot-care. The pooled meta-analysis showed that 58\% (95\% CI: 41, 74\%) of diabetic patients practiced good diabetic foot-care practice (Fig. 6).

\section{Discussion}

This systematic review and meta-analysis was conducted to assess the level of self-care practice among diabetic patients in Ethiopia (including major four domains: like food choices, physical activity, foot care, and blood glucose monitoring). Accordingly, almost half (49\%) of diabetic patients in Ethiopia practice the recommended levels of diabetes self-care. This finding was much lower than a study in Nigeria (80\%), Thailand (87\%), and Iran (74\%) [55-57], and higher than the study reported in Kenya (41\%) [58]. The difference in culture and economical status, lifestyle difference, and difference in the access to health care facilities and level of education of the general public could be the reasons for the difference. Furthermore, varied methods applied to measure outcome-parameters among countries may be contribute the variation of findings. Diabetes self-care practice

Table 3 Meta-regression output to explore heterogeneity of the pooled prevalence of diabetes self-care practice among diabetic patients in Ethiopia

\begin{tabular}{llll}
\hline Variables & Coefficients & P-value & 95\% conf. Interval \\
\hline Publication year & -0.5710 & 0.732 & -4.0722 .930 \\
Sample size & 0.0078 & 0.819 & -0.6470 .080 \\
\hline
\end{tabular}

demands the involvements of individuals with diabetes and health care providers to increase the adherence of good practice through increasing the knowledge and understanding of the disease and predicting the long-term impacts of the disease. However, difference in the level of education among diabetic patients across the countries, the level of understanding of health care works on diabetes self-care should contribute for the variation diabetes self-care practice across the countries mentioned above.

In this meta-analysis, 50\% (95\% CI: 42, 58\%) of participants have practicing the recommended diet (grains and starchy vegetables, Non-starchy vegetables etc). Similar finding was reported in India (46\%) [59]. However, the finding of the current study is higher than the figure reported in Yemen (21\%) and Pakistan (17\%) [60, 61]. The discrepancy might be explained due to socio-cultural difference, difference in the types of foods available with different nutritional value, as well as level of education provided for diabetic patients. The importance of following a regular dietary plan in terms of both quantity and quality lies in the fact that adequate blood sugar control and proper weight management are linked to it. The World Health Organization (WHO) recommends a minimum of $400 \mathrm{~g}$ of fruit and vegetables per day [62]. ADA also recommends 45 to $65 \%$ of daily total calorie for patients who are suffering with diabetes [6].

This meta-analysis identify that self-monitoring of blood glucose was a least practice in Ethiopia with pooled prevalence of $28 \%$. This finding was much lower than a report in Alexandria which $64.7 \%$ had good compliance of blood glucose control [63]. This low adherence to SMBG practices could probably be attributed to relevant financial barriers to acquisition of glucometer or to undergo a check-up at a health facility [64]. Most patients, who had access to a glucometer at home, checked their glucose level only once a month or at no regular interval $[65,66]$.

In this meta-analysis almost half (49\%) of diabetic patients were engaged in the recommended physical activity. Physical exercise has been considered a cornerstone of diabetes management, along with diet and medication 


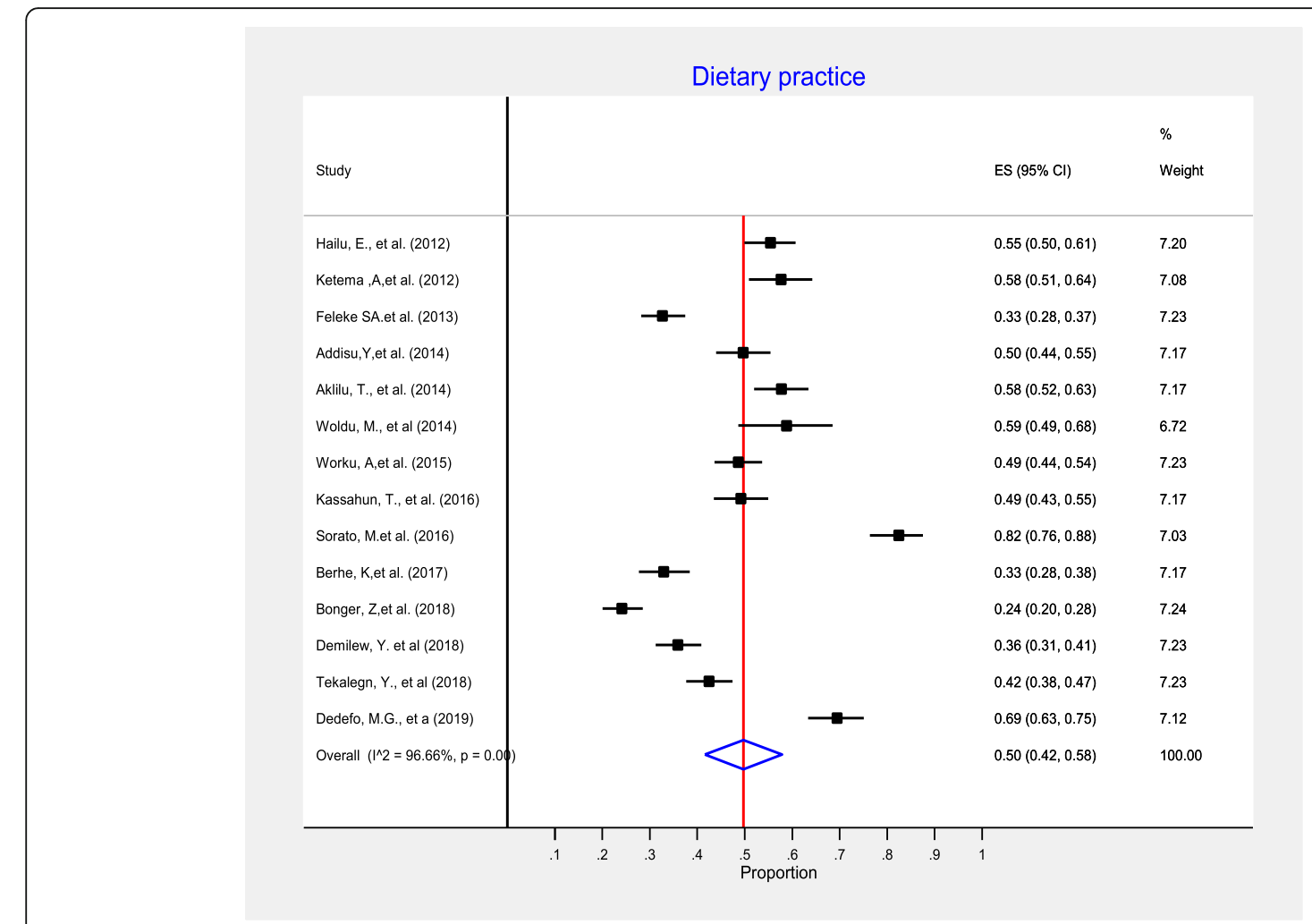

Fig. 3 Meta-analysis (forest plot) of the proportion of good dietary self-care practice among diabetic patients in Ethiopia

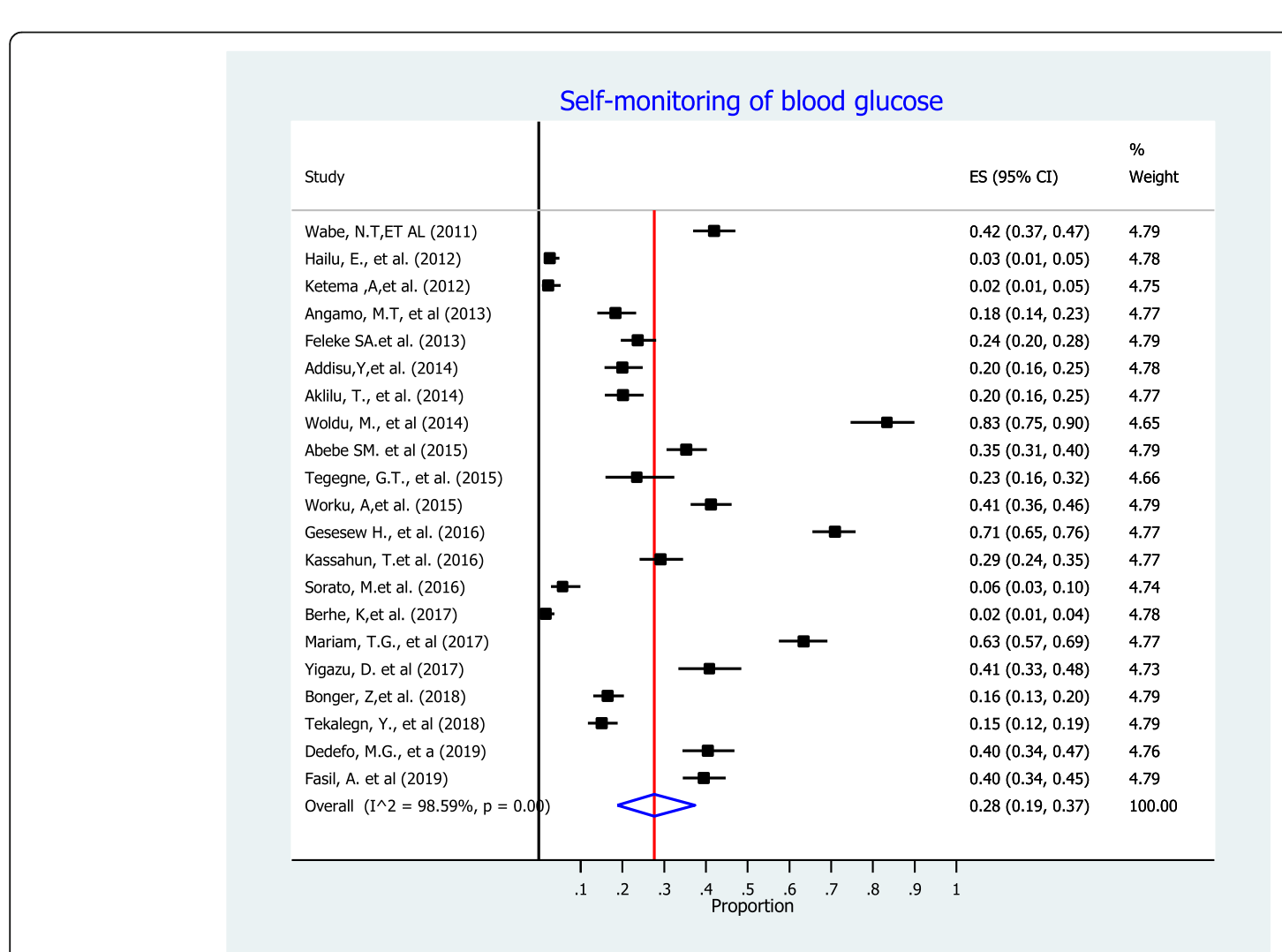

Fig. 4 Meta-analysis (forest plot) of the proportion of good practice of self-monitoring of bloodglucose among diabetic patients in Ethiopia. 


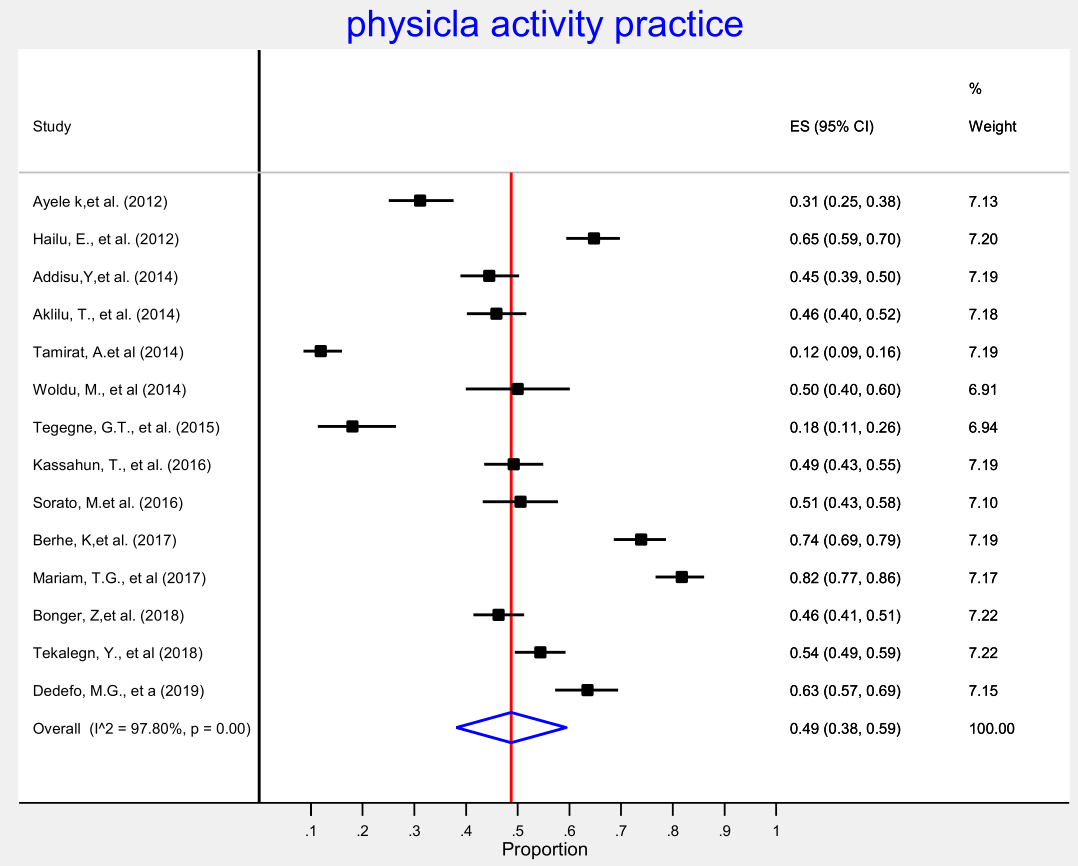

Fig. 5 Forest plot of pooled proportion of adequate physical activity among diabetic patients in Ethiopia

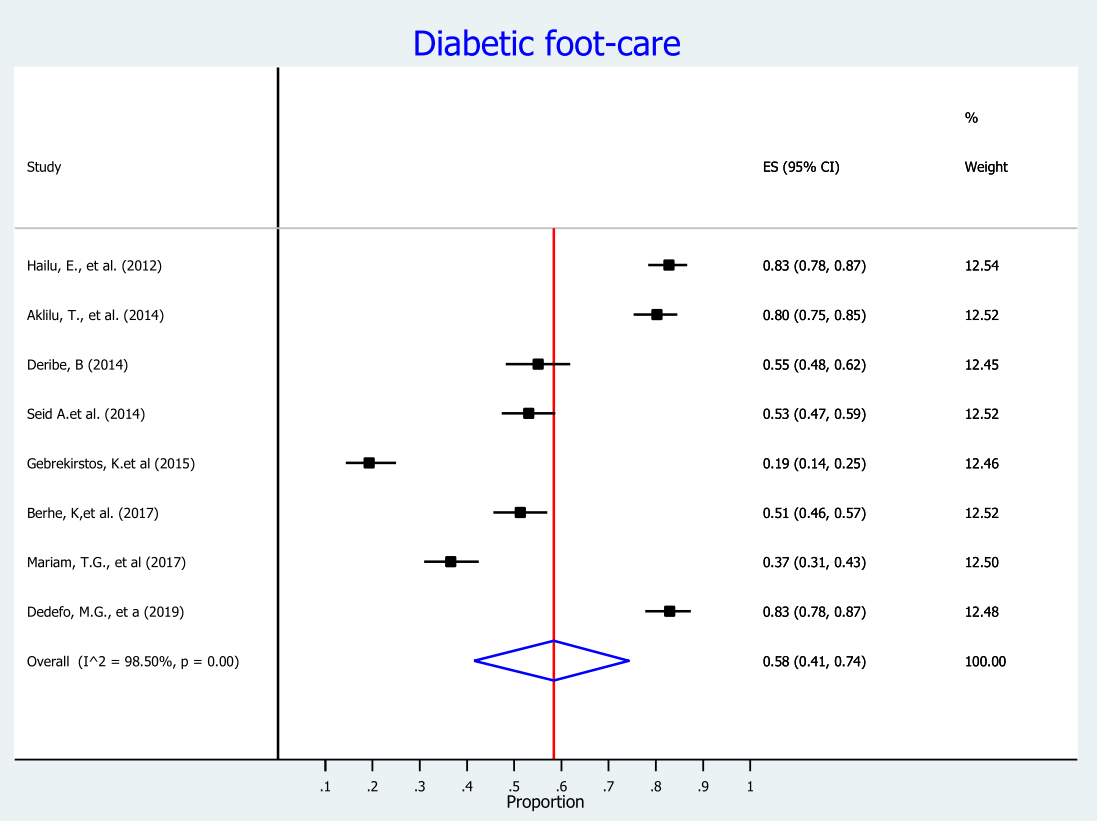

Fig. 6 Forest plot of the pooled proportion of good foot-care practice among diabetic patients in Ethiopia 
[67]. This finding was almost comparable with a report at USA (39\%) [68]. The discrepancy could be explained by the time difference of the research carried out. The evidence reported from USA was conducted in 2007. Whereas almost all included studies which measured physical activity practice of DM patients in this metaanalysis were conducted at the mean year of 2015. Since various initiatives nationally and internationally (Ethiopia Diabetic Associating (EDA), Ministry of Health $(\mathrm{MOH}))$ have been instigated by several organizations between these motioned time period, the proportion of diabetic patients who were engaged in the recommended physical activity could be increased. Researches have shown that physical activity can lower bad cholesterol and raise good cholesterol, improve body's ability to use insulin [50, 67, 69]. Exercise have also beneficial effect for diabetic patients to reduce the development of cardiovascular complication with regard to glucose control [70].

In this meta-analysis, more than half of diabetes patients have good foot-care practice with pooled prevalence of $58 \%$ (95\% CI:41, 74\%). This finding was comparable with findings from Siri Lanka (53\%) and South Africa (69.2\%) [71]. However,the finding was much higher than the study reported in Nigeria (10\%) [72]. This discrepancy could be explained by diabetic foot care involves many different professionals and the patient presentations also diverse. Successful management of diabetic foot problem needs the expertise of multidisciplinary team with implementation of universal good care. This involves good attitude of healthcare professionals, patients and health-care system.

\section{Limitation of the study}

This systematic review and meta-analysis have certain limitations. First, methods applied to measure outcomeparameters varied among included studies. Second, included studies used self-report as a measure of outcomes, and this may have introduced bias. Multiple methods may be required to detect those who report good practice but who may in fact may have poor practice.

\section{Conclusion}

More than half of diabetic patients had poor diabetes self-care practice. Therefore, health care personnel and Ethiopian Diabetic Association (EDA) should increase the patient's awareness to the importance of self-care practices domains and strongly promote the practice among diabetes patients by strengthening different local program working on diabetes. Future efforts and resource investments in public health system need to strengthen the distribution of structured diabetes-care programs which need to be adapted to the Ethiopiacontext.

\section{Supplementary information}

Supplementary information accompanies this paper at https://doi.org/10. 1186/s12889-020-8425-2.

Additional File 1. Over all diabetic self-care data set.

Additional File 2. Dietary practice data set.

Additional File 3. Self-monitoring blood glucose dataset.

Additional File 4. Physical activity data set.

Additional File 5. Diabetic foot-care data set.

\section{Abbreviations}

ADA: American diabetes association; Cl: Confidence interval; EDA: Ethiopia diabetes association; PRISMA: Preferred reporting items for systematic reviews and meta-analyses; SE: Standard error; SMBG: Self-monitoring of blood glucose; SNNPR: South nation and nationalities people of the region; WHO: World health organization

\section{Acknowledgments}

We would like to thank all authors of the primary studies included in this systematic review and meta- analysis.

\section{Availability of data and material}

All data analysed during this study are included in its supplementary information files.

\section{Authors' contributions}

DBK and AA: Conception of research protocol, study design, literature review, data extraction, data analysis, interpretation and drafting the manuscript. AAA, GDK, GMK, MAA and CTL: data analysis, reviewing the manuscript, data extraction and quality assessment. All authors have read and approved the manuscript.

\section{Funding}

No funding was obtained for this study.

Ethics approval and consent to participate Not applicable.

Consent for publication

Not applicable.

\section{Competing interests}

The authors declare that they have no competing interests.

\section{Author details}

${ }^{1}$ Department of Public Health, College of Health Sciences, Debre Markos University, P.O. Box 269, Debre Markos, Ethiopia. ${ }^{2}$ Department of Nutrition and Food Science, College of Health Sciences, Debre Markos University, Debre Markos, Ethiopia. ${ }^{3}$ Department of Nursing, College of Health Sciences, Debre Markos University, Debre Markos, Ethiopia.

Received: 9 September 2019 Accepted: 27 February 2020

Published online: 12 March 2020

References

1. Ayele K, et al. Self care behavior among patients with diabetes in Harari, eastern Ethiopia: the health belief model perspective. PLoS One. 2012;7(4): e35515.

2. Kassahun CW, Mekonen AG. Knowledge, attitude, practices and their associated factors towards diabetes mellitus among non diabetes community members of Bale Zone administrative towns, South East Ethiopia. A cross-sectional study. PloS one. 2017;12(2):e0170040.

3. International Diabetes Federation. IDF diabetes atlas 2017. Eighth edition. Brussels: International Diabetes Federation; 2017. 
4. Aklilu T, et al. Diabetic Patients' knowledge of their disease, therapeutic goals, and self-management: association with goal attainment at Dessie referral hospital. Ethiopia Ther Innov Regul Sci. 2014;48(5):583-91.

5. Sobngwi $E$, et al. Diabetes in Africans. Part 1: epidemiology and clinical specificities. Diabetes Metab. 2001;27(6):628-34.

6. American Diabetes Association. I.c., and promoting health in populations, Standards of medical care in diabetes-2018. USA: Diabetes Care: The Journal of Clinical and Applied Research and Education; 2018.

7. Shrivastava SR, Shrivastava PS, Ramasamy J. Role of self-care in management of diabetes mellitus. J Diabetes Metab Disord. 2013;12(1):14.

8. Wagner $\mathrm{EH}$, et al. Improving chronic illness care: translating evidence into action. Health Aff. 2001;20(6):64-78.

9. Glasgow RE, Strycker LA. Preventive care practices for diabetes management in two primary care samples. Am J Prev Med. 2000;19(1):9-14.

10. Peyrot M, et al. Psychosocial problems and barriers to improved diabetes management: results of the cross-National Diabetes Attitudes, wishes and needs (DAWN) study. Diabet Med. 2005;22(10):1379-85.

11. Group, U.P.D.S. Intensive blood-glucose control with sulphonylureas or insulin compared with conventional treatment and risk of complications in patients with type 2 diabetes (UKPDS 33). Lancet. 1998;352(9131):837-53.

12. Ohkubo $Y$, et al. Intensive insulin therapy prevents the progression of diabetic microvascular complications in Japanese patients with non-insulindependent diabetes mellitus: a randomized prospective 6-year study. Diabetes Res Clin Pract. 1995;28(2):103-17.

13. Toobert, D., R. Glasgow, and C. Bradley, Handbook of psychology and diabetes. Chur, Switzerland: Harwood Academic, 1994: p. 351-375.

14. Johnson SB. Health behavior and health status: concepts, methods, and applications. J Pediatr Psychol. 1994;19(2):129-41.

15. McNabb WL. Adherence in diabetes: can we define it and can we measure it? Diabetes Care. 1997;20(2):215-8.

16. Fasil A, Biadgo B, Abebe M. Glycemic control and diabetes complications among diabetes mellitus patients attending at University of Gondar Hospital. Northwest Ethiop Diabtes Metab Syndr Obes. 2019;12:75-83.

17. Yigazu DM, Desse TA. Glycemic control and associated factors among type 2 diabetic patients at Shanan gibe hospital. Southwest Ethiopia BMC Res Notes. 2017;10(1):597.

18. Mora S, et al. Association of physical activity and body mass index with novel and traditional cardiovascular biomarkers in women. Jama. 2006; 295(12):1412-9.

19. Physical Activity Guidelines Advisory Committee report. To the secretary of health and human services. Part a: executive summary. Nutr Rev, 2009. 2008; 67(2):114-20

20. Abate TW, Tareke M, Tirfie M. Self-care practices and associated factors among diabetes patients attending the outpatient department in Bahir Dar. Northwest Ethiopia BMC Res Notes. 2018;11(1):800.

21. Addisu Y, Eshete A, Hailu E. Assessment of diabetic patient perception on diabetic disease and self-care practice in Dilla University referral hospital. South Ethiopia J Metabolic Synd. 2014;3(166):2167-0943.1000166.

22. Amente $\mathrm{T}$, et al. Self care practice and its predictors among adults with diabetes mellitus on follow up at Nekemte hospital diabetic clinic, West Ethiopia. World J Med Med Sci. 2014;2(3):1-16.

23. Berhe KK, et al. Assessment of self care management and its associated factors among type 2 diabetes patients in Mekelle hospital and Ayder referral hospitals, Mekelle City, Tigray, northern Ethiopia, 2012/13. Glob J Med Res. 2017;17(1):2249-4618

24. Chali SW, Salih MH, Abate AT. Self-care practice and associated factors among diabetes mellitus patients on follow up in Benishangul Gumuz regional state public hospitals, Western Ethiopia: a cross-sectional study. BMC Res Notes. 2018:11(1):833.

25. Dedefo MG, et al. Self-care practices regarding diabetes among diabetic patients in West Ethiopia. BMC Res Notes. 2019:12(1):212.

26. Deribe B, Woldemichael K, Nemera G. Prevalence and factors influencing diabetic foot ulcer among diabetic patients attending Arbaminch hospital. South Ethiopia J Diabetes Metab. 2014;5(1):1-7.

27. Feleke SA, et al. Assessment of the level and associated factors with knowledge and practice of diabetes mellitus among diabetic patients attending at FelegeHiwot hospital. Northwest Ethiopia Clin Med Res. 2013; 2(6):110

28. Kassahun T, Eshetie T, Gesesew H. Factors associated with glycemic control among adult patients with type 2 diabetes mellitus: a cross-sectional survey in Ethiopia. BMC Res Notes. 2016;9(1):78.
29. Kassahun T, et al. Diabetes related knowledge, self-care behaviours and adherence to medications among diabetic patients in Southwest Ethiopia: a cross-sectional survey. BMC Endocr Disord. 2016;16(1):28.

30. Mamo M, Demissie M. Self care practice and its associated factors among diabetic patients in addisababa public hospitals, cross sectional study. J Diabetes Cholest Metabol. 2016;1(1):2-5.

31. Mariye T, et al. Magnitude of diabetes self-care practice and associated factors among type two adult diabetic patients following at public hospitals in central zone, Tigray region, Ethiopia, 2017. BMC Res Notes. 2018;11(1):380.

32. Niguse $H$, et al. Self-care related knowledge, attitude, practice and associated factors among patients with diabetes in Ayder comprehensive specialized hospital, North Ethiopia. BMC Res Notes. 2019;12(1):34.

33. Sorato MM, Tesfahun C, Lamessa D. Levels and predictors of adherence to self-care behaviour among adult type 2 diabetics at Arba Minch general hospital. Southern Ethiopia J Diabetes Metab. 2016;7(6):11.

34. Tiruneh SA, et al. Factors influencing diabetes self-care practice among type 2 diabetes patients attending diabetic care follow up at an Ethiopian general hospital, 2018. J Diabetes Metab Disord. 2019;18(1):199-206.

35. Woldu $\mathrm{M}$, et al. Factors associated with poor glycemic control among patients with type 2 diabetes mellitus in ambo hospital. Ambo; Ethiopia Endocrinol Metab Synd. 2014:3(143):2161-1017.1000143.

36. PRISMA. Preferred Reporting Items for Systematic Reviews and MetaAnalyses (PRISMA) 2009 [cited 2020 21]; Available from: http://www.prismastatement.org/.

37. Hailu E, et al. Self-care practice and glycaemic control amongst adults with diabetes at the Jimma University Specialized Hospital in south-west Ethiopia: A cross-sectional study. Afr J Prim Health Care Fam Med. 2012;4(1):6.

38. Seid A, Tsige Y. Knowledge, practice, and barriers of foot care among diabetic patients attending Felege Hiwot referral hospital, Bahir Dar. Northwest Ethiopia Adv Nurs. 2015;2015:9.

39. The modified Newcastle Ottawa scale for cross sectional studies. Available from: https://journals.plos.org/plosone/article/file?type=supplementary\&id= info:doi/https://doi.org/10.1371/journal.pone.0136065.s004.

40. Rücker $\mathrm{G}$, et al. Undue reliance on I 2 in assessing heterogeneity may mislead. BMC Med Res Methodol. 2008;8(1):79.

41. Barendregt JJ, et al. Meta-analysis of prevalence. J Epidemiol Community Health. 2013;67(11):974-8.

42. Tekalegn $Y$, et al. Magnitude of glycemic control and its associated factors among patients with type 2 diabetes at Tikur Anbessa specialized hospital, Addis Ababa. Ethiopia PLoS One. 2018;13(3):e0193442.

43. Worku A, Abebe SM, Wassie MM. Dietary practice and associated factors among type 2 diabetic patients: a cross sectional hospital based study, Addis Ababa. Ethiopia SpringerPlus. 2015;4(1):15.

44. Demilew YM, Alem AT, Emiru AA. Dietary practice and associated factors among type 2 diabetic patients in Felege Hiwot regional referral hospital, Bahir Dar. Ethiopia BMC Res Notes. 2018;11(1):434.

45. Bonger Z, Shiferaw S, Tariku EZ. Adherence to diabetic self-care practices and its associated factors among patients with type 2 diabetes in Addis Ababa. Ethiopia Patient Preference Adherence. 2018;12:963.

46. Mariam TG, et al. Prevalence of diabetic foot ulcer and associated factors among adult diabetic patients who attend the diabetic follow-up clinic at the University of Gondar Referral Hospital, North West Ethiopia, 2016: Institutional-based cross-sectional study. J Diabetes Res. 2017:2017:8.

47. Gebrekirstos K, Gebrekiros S, Fantahun A. Prevalence and factors associated with diabetic foot ulcer among adult patients in ayder referral hospital diabetic clinic mekelle, North Ethiopia, 2013. J Diabetes Metab. 2015;6(579):2.

48. Gurmu Y, Gela D. Factors associated with self-care practice among adult diabetes patients in west Shoa zone, Oromia regional state, Ethiopia. BMC Health Serv Res. 2018;18(1):732.

49. Tegegne, G.T., et al., Glycemic control and self-care practice among ambulatory diabetic patients in ambo general hospital, West Showa, Ethiopia. Global Journal of Medical Research, 2015.

50. Tamirat A, Abebe L, Kirose G. Prediction of physical activity among Type-2 diabetes patients attending Jimma University specialized hospital, Southwest Ethiopia: application of health belief model. Science. 2014;2(6):524-31.

51. Wabe NT, Angamo MT, Hussein S. Medication adherence in diabetes mellitus and self management practices among type-2 diabetics in Ethiopia. N Am J Med Sci. 2011:3(9):418.

52. Angamo MT, Melese BH, Ayen WY. Determinants of glycemic control among insulin treated diabetic patients in Southwest Ethiopia: hospital based cross sectional study. PLoS One. 2013;8(4):e61759. 
53. Abebe SM, et al. Level of sustained glycemic control and associated factors among patients with diabetes mellitus in Ethiopia: a hospital-based crosssectional study. Diabetes, Metab Syndr Obes: Targets Ther. 2015;8:65.

54. Worku A, Mekonnen Abebe S, Wassie MM. Dietary practice and associated factors among type 2 diabetic patients: a cross sectional hospital based study, Addis Ababa. Ethiopia. SpringerPlus. 2015;4(1):15.

55. Yekta Z, et al. Assessment of self-care practice and its associated factors among diabetic patients in urban area of Urmia, northwest of Iran. J Res Health Sci. 2011;1(1):33-8.

56. Okolie VU, et al. Knowledge of diabetes management and control by diabetic patients at Federal Medical Center Umuahia Abia State, Nigeria. Int J Med Med Sci. 2009;1 (9):353-8

57. Kaehaban S, Hongsranagon P, Havanond P. Factors influencing self-care behaviors of diabetic patients in diabetes mellitus clinic, Changhan hospital, Roi Et Province. Thai J Health Res. 2010:24(Suppl. 1):21-6.

58. Maina, W.K., et al., Knowledge, attitude and practices related to diabetes among community members in four provinces in Kenya: a cross-sectional study. Pan Afr Med J, 2010. 7(1).

59. Rajasekharan $\mathrm{D}$, et al. Self care activities among patients with diabetes attending a tertiary care hospital in Mangalore Karnataka, India. Ann Med Health Sci Res. 2015;5(1):59-64.

60. ALhariri A, Daud F, Saghir SAM. Factors associated with adherence to diet and exercise among type 2 diabetes patients in Yemen. Diabetes Manag. 2017;7(3):264-71.

61. Bano A, et al. Dietary knowledge, attitude and practices of diabetes patients at services hospital Lahore. Int J Appl Sci Biotechnol. 2017:5(2):227-36.

62. World Health Organization (WHO) and FAO a joint Initiative to promote fruit and vegetables for health worldwide. 2019; Available from: https://www. who.int/dietphysicalactivity/fruit/en/.

63. Kamel $\mathrm{N}$, et al. Sociodemographic determinants of management behaviour of diabetic patients. Part I Behav Patients Relat Manage Dis EMHJ-East Mediterr Health J. 1999:5(5):967-73 1999.

64. Stephani V, Opoku D, Beran D. Self-management of diabetes in sub-Saharan Africa: a systematic review. BMC Public Health. 2018;18(1):1148.

65. Awodele O, Osuolale JA. Medication adherence in type 2 diabetes patients: study of patients in Alimosho general hospital, Igando, Lagos, Nigeria. Afr Health Sci. 2015;15(2):513-22

66. Abdelgadir $\mathrm{M}$, et al. The influence of glucose self-monitoring on glycaemic control in patients with diabetes mellitus in Sudan. Diabetes Res Clin Pract. 2006;74(1):90-4

67. Sigal RJ, et al. Physical activity/exercise and type 2 diabetes: a consensus statement from the American Diabetes Association. Diabetes Care. 2006; 29(6):1433-8.

68. Morrato EH, et al. Physical activity in US adults with diabetes and at risk for developing diabetes, 2003. Diabetes Care. 2007;30(2):203-9.

69. Hu G, et al. Physical activity in the prevention of type 2 diabetes. Kardiovaskuläre Medizin. 2004;7(11):394-405

70. Marwick TH, et al. Exercise training for type 2 diabetes mellitus: impact on cardiovascular risk: a scientific statement from the American Heart Association. Circulation. 2009:119(25):3244-62.

71. Dikeukwu R, Omole OB. Awareness and practices of foot self-care in patients with diabetes at Dr Yusuf Dadoo district hospital, Johannesburg. J Endocrinol Metab Diabetes S Afr. 2013;18(2):112-8.

72. Desalu, O, et al. Diabetic foot care: self reported knowledge and practice among patients attending three tertiary hospital in Nigeria. Ghana Med J, 2011. 45(2).

\section{Publisher's Note}

Springer Nature remains neutral with regard to jurisdictional claims in published maps and institutional affiliations.

Ready to submit your research? Choose BMC and benefit from:

- fast, convenient online submission

- thorough peer review by experienced researchers in your field

- rapid publication on acceptance

- support for research data, including large and complex data types

- gold Open Access which fosters wider collaboration and increased citations

- maximum visibility for your research: over $100 \mathrm{M}$ website views per year

At $\mathrm{BMC}$, research is always in progress.

Learn more biomedcentral.com/submissions 